\title{
State of the art lecture: EUS for esophageal tumors
}

W. A. Marsman, P. Fockens

Dept. of Experim. Hepatology, Academic Medical Center, Amsterdam

\section{Introduction}

Treatment and outcome of patients with esophageal cancer is stage dependent. Since its introduction in the early 1980 s, EUS has played a central role in the staging of esophageal cancer. Adequate staging of esophageal cancer is important in the initial triage of patients to receive immediate surgery, neoadjuvant therapy or palliative treatment only. Also in patients with early cancer, EUS can be used to evaluate the possibility of endoscopic mucosal resection. EUS remains superior in $\mathrm{T}$ - and $\mathrm{N}$-staging of esophageal cancer compared to other imaging modalities such as CT, PET and MRI. New developments will hopefully further improve the staging of early lesions, stenotic lesions and the diagnostics of lymph node metastases. Nowadays many patients are being treated with neoadjuvant chemo-radiotherapy. EUS could also play a role in the assessment of these therapies and to give direction towards further management.

\section{EUS-technique}

Instruments. EUS equipment consists of radial (mechanical or electronic) and curved linear (electronic) echoendoscopes. The image created by the radial echoendoscopes is in a $360^{\circ}$ transverse plane, perpendicular to the long axis of the echoendoscope. Recent generation mechanical radial echoendoscopes have broadband frequencies ranging from 5 to $20 \mathrm{MHz}$. The electronic echoendoscopes have adjustable frequencies from 5 to $10 \mathrm{MHz}$ (Fig. 1).

Linear instruments scan along the long axis of the endoscope, which enables real-time visualization of a needle exiting from the biopsy channel into a target such as a lymph node or organ.

Correspondence: Dr. med. W. A. Marsman · Dept. of Experim. Hepatology Academic Medical Center · Meibergdreef 9 - 1105 AZ Amsterdam · The Netherlands

Bibliography: Endoscopy 2006; 38 (S1): S17-S21 c Georg Thieme Verlag KG Stuttgart · New York · ISSN 0013-726X · DOI 10.1055/s-2006-946645 


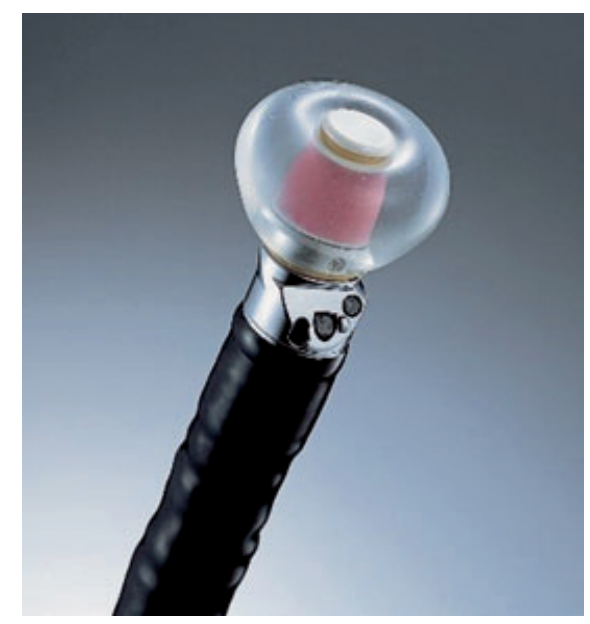

Fig. 1 Radial electronic echoendoscope.

In the electronic instruments the image orientation and staging can be assisted by the addition of pulsed, color and power Doppler.

For high resolution imaging of the gut wall high frequency transducers $(12-30 \mathrm{MHz})$ can be used. These are transducers incorporated in small catheters and are mechanically rotated. They are advanced through the working channel of an endoscope into the lumen of the gut (Fig. 2). High resolution imaging of the gut wall is an important tool for the evaluation of patients selected for endoscopic mucosal resection of early cancers of the esophagus and stomach [1].

High grade stenotic tumors can often not be evaluated by a regular echoendoscope. In these patients either pre-EUS dilatation is required in order to pass the echoendoscope. This has been associated with significant complications, such as perforations, in the past [2]. An alternative option is a $8 \mathrm{~mm}$ non-optic $7.5 \mathrm{MHz}$ probe, which is advanced through the tumor over a previously placed guidewire [3]. This option enables adequate staging without dilatation.

EUS-FNA. Once a suspicious lymph node or liver lesion is identified on EUS, EUS-FNA can be performed in order to confirm the presence of metastasis. EUS-FNA is performed with a linear echoendoscope. Doppler ultrasound can be used to ensure that there are no interposed vessels. The FNA needle system, consisting of a 19, 22- or 25-gauge needle, is inserted through the working channel of the endoscope and advanced through the gut wall into the suspicious lesion under endosonographic guidance

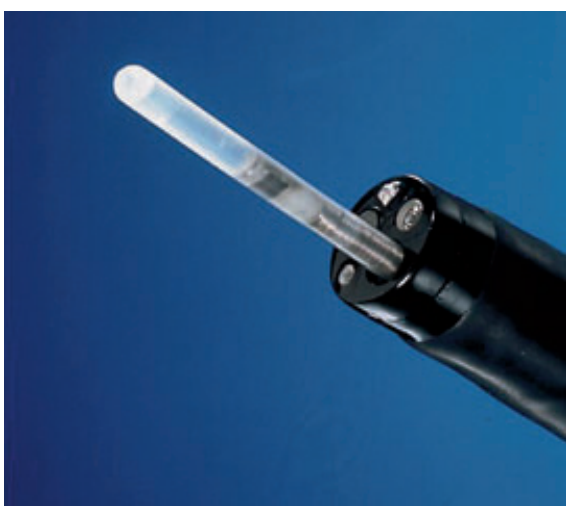

Fig. 2 High frequency transducer through working channel of an endoscope.
(Fig. 3). The stylet is removed and suction can be applied with a $10-\mathrm{ml}$ syringe while the needle is manipulated back and forth within the target lesion. The aspirate is placed on a glass slide and processed with a Diff-Quick stain. On site interpretation of the specimen by a cytologist is preferable to evaluate for adequacy of the specimen and to minimize the number of needle passes. The pathologist will do eventual evaluation of the presence of malignant cells after fixation and a Giemsa or other staining. Recently trucut needles have been introduced to obtain histological samples of lymph nodes and lesions of the pancreas [4]. In small series that have been published so far, this technique was shown to be safe without significant complications, but its role and superiority in comparison to FNA remains to be determined. We fear that standard use of these needles will carry the risk of a higher complication rate.

\section{Accuracy of EUS}

TNM staging system. Esophageal cancer is usually treated according to tumor stage as defined by the TNM system developed by the American Joint Commission on Cancer [5]. The TNM system is based on the determination of depth of tumor invasion ( $T$ stage), the presence or absence of regional lymph node metastasis ( $\mathrm{N}$ stage), and the presence or absence of distant metastasis (M-stage). Multiple minimally or noninvasive modalities exist to help in the clinical staging of esophageal cancer, including EUS, CT, MRI and PET-scanning. EUS has taken a central role in the locoregional staging of esophageal cancer, because of its accuracy of tumor invasion and detection of regional lymph node metastasis. Although EUS is superior to PET and CT for locoregional staging, the latter modalities are better at detecting liver and lung metastasis. Therefore it is logical to perform EUS when PET and CT have not revealed distant metastasis. This may help to triage the patient to surgery alone, neoadjuvant therapy followed by surgery or palliative treatment only. A recent study has shown that the combination of CT, PET and EUS reduces the number of unnecessary operation from $44 \%$ to $21 \%$ [6].

Tumor. The depth of tumor invasion and the involvement of the esophageal wall layers determine T stage. The earliest stage, Tis or carcinoma in situ is present when the cancer is limited to the epithelium and the lamina propria is intact. This stage usually can only be detected by biopsy and is quite often not visible on EUS. T1 tumors are defined when cancerous cells invade the lamina propria or submucosa. With the advent of high frequency catheter probes, T1 tumors have been further classified in to $\mathrm{T} 1 \mathrm{~m}$ (confined to mucosa) or T1sm (tumor invading submucosa).

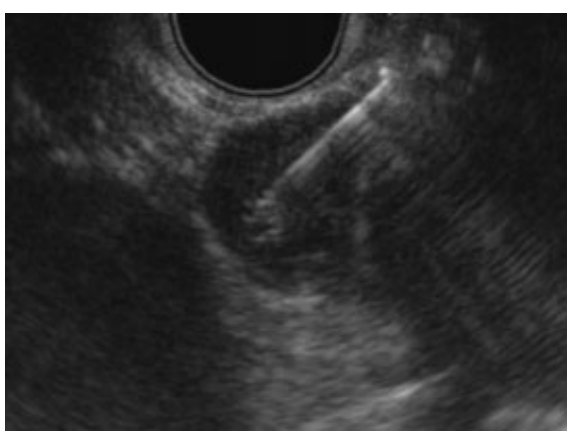

Fig. 3 FNA of a suspicious lymph node. 


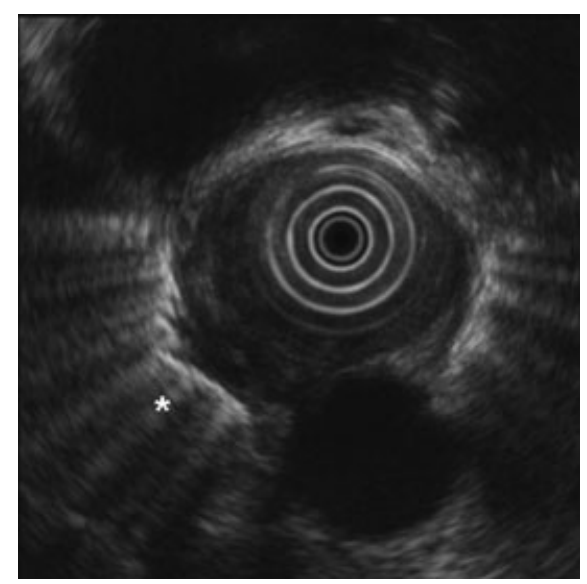

Fig. 4 T4 esophageal cancer with ingrowth of the pleura at the asterix.

A T1 sm lesion has a 20 - 35\% rate of lymph node metastasis and is therefore not suitable for local endoscopic therapy [7]. The accuracy of high frequency probes in distinguishing between mucosal cancer and cancer invading the submucosa has been reported $81 \%-100 \%$ [1]. Pathological evaluation of an EMR specimen will eventually lead to the decision whether the local endoscopic therapy is sufficient or whether a patient needs a surgical esophagectomy with a lymph node dissection. When the tumor has invaded the muscularis propria, the tumor is classified as T2. When the tumor further progresses to invade the adventitia, the tumor is classified as T3. Involvement of mediastinal structures, such as the aorta, pleura, azygos vein, or any other adjacent structure, is classified as T4 disease (Fig. 4). In a meta-analysis it was demonstrated that EUS was significantly more accurate than CT in identifying stages T1 through T4 [8]. CT is unable to accurately differentiate between the T-stages of the disease, a distinction important when considering the use of neoadjuvant therapy [9]. The accuracy of EUS and CT for various T stages is shown in Table 1.

Locoregional lymph nodes. Due to rich (peri-)esophageal lymphatics, esophageal cancer has the propensity for early spread to local lymph nodes. It has been clearly shown that patients with $\mathrm{N} 1$ disease as classified by EUS have poorer survival than those with N0 disease [10]. Furthermore the number of detected lymph nodes is an important predictor of survival [11]. Lymph node characteristics on EUS can be helpful in classifying benign from malignant lymph nodes. Criteria for malignant lymph nodes include diameter greater than $10 \mathrm{~mm}$, uniform hypoechogenicity, a rounded shape, and nodes with a sharp border [12]. Given the subjective nature of these criteria, EUS is generally less accurate in identifying malignant nodes than in evaluating depth of tumor invasion. In a meta-analysis of Kelly et al, the accuracy of conventional EUS for N staging was $79 \%$ only [13]. Studies com-

Table 1 Comparison of accuracy of CT and EUS in the locoregional staging of esophageal cancer. Adapted from Rosch [8]

\begin{tabular}{llll}
\hline Technique & No. of patients & Taccuracy (\%) & N accuracy (\%) \\
\hline CT & 1154 & $45(40-50)$ & $54(48-71)$ \\
\hline EUS & 1035 & $85(59-92)$ & $77(50-90)$ \\
\hline
\end{tabular}

Table 2 Comparison of accuracy of CT, EUS, and EUS-FNA in preoperative lymph node staging of patients with esophageal cancer. Adapted from Vazquez-Sequeiros [18]

\begin{tabular}{llll}
\hline Technique & Sensitivity (\%) & Specificity (\%) & Accuracy (\%) \\
\hline CT & $29(17-44)$ & $89(72-98)$ & $51(40-63)$ \\
\hline EUS & $71(56-83)$ & $79(59-92)$ & $74(62-83)$ \\
\hline EUS-FNA & $83(70-93)$ & $93(77-99)$ & $87(77-94)$ \\
\hline
\end{tabular}

paring EUS with CT for regional lymph node metastasis have consistently demonstrated that EUS is more accurate for $\mathrm{N}$ staging (Table 2). The use of EUS-guided fine-needle aspiration (EUSFNA) is now becoming more widespread, and has shown to improve the accuracy of EUS for $\mathrm{N}$ staging by providing cytological involvement of lymph nodes [14]. In this prospective study EUSFNA for lymph node metastases had a sensitivity and specificity of $98,3 \%$ and $100 \%$ respectively, which compared favorable compared to EUS alone.

Celiac axis lymph nodes. The detection of celiac axis lymph node (CLN) metastasis has an important implication for patients with esophageal cancer. In patients with distal esophageal cancer, CLN metastasis are classified as M1a. In mid- or proximal tumors CLN metastasis are staged M1b, similar to liver metastases. Patients with esophageal cancer and CLN metastasis have worse survival than those without CLN involvement [15]. In addition it is doubtful whether patient with celiac lymph node metastasis benefit from a surgical resection [16]. In patients with esophageal cancer, the identification of CLNs was virtually synonymous with malignant involvement. Regardless of echo features and size, $90 \%$ of all detected CLNs were proven to be malignant in one study [17]. Moreover, $100 \%$ of lymph nodes greater than $1 \mathrm{~cm}$ in size were malignant. The clinical impact that malignant CLNs have on therapy leads to the necessity to perform EUS-FNA, providing proof of malignant involvement prior to neoadjuvant therapy [18]. The detection of metastasis in celiac lymph nodes by EUS-FNA has a reported sensitivity of $98 \%$ and specificity of $100 \%[17]$.

Liver metastasis. EUS can detect occult liver metastases in patients in whom non-invasive hepatic imaging studies are normal, although the frequency with which such lesions are detected is low [19]. EUS of the liver is best performed with linear instruments and provides excellent imaging of the medial two-thirds of the liver, but cannot exclude metastatic disease to all areas of the liver. Metastases usually appear as discrete relatively hypoechoic lesions in the liver. Once identified, EUS-FNA can be performed, yielding important diagnostic and prognostic information for the patient management.

Restaging. The use of neoadjuvant chemoradiotherapy continues to be an area of active investigation and is becoming more widespread for patients with advanced disease. The ability to assess the response to neoadjuvant therapy is potentially important for further clinical management. Initial studies on preoperative chemoradiotherapy were promising, however these studies were small and the neoadjuvant therapy was ineffective in 
downstaging the tumor [20]. More effective neoadjuvant modalities have now been developed which are effective in downstaging of the tumor. In this setting EUS has shown considerably less accuracy for restaging of the disease [21-22]. The most frequent error was overstaging, apparently because the fibrosis and inflammation associated with chemoradiotherapy are indistinguishable from residual microscopic foci of cancer within the esophageal wall. Although the tumor stage cannot be reliably established by EUS after neoadjuvant therapy, several studies have shown that reduction in crossectional area of the tumor by more than $50 \%$ is associated with a response to therapy [23]. But also simply measuring the maximal tumor diameter before and after neoadjuvant therapy can correctly identify the responders and nonresponders [24]. Re-staging of lymph nodes with EUS-FNA may become more important in the near future.

\section{Clinical impact}

Although EUS is superior to alternative staging modalities, the utility of EUS staging to alter clinical management of patients and improve outcome has only recently been investigated. The clinical outcome of patients with esophageal cancer before and after the introduction of EUS has demonstrated that the use of EUS is associated with an advantage in recurrence free survival and overall survival [25]. This benefit appeared to be related to the increased administration of chemoradiotherapy through more accurate preoperative staging. The use of EUS has also resulted in an increased referral for nonsurgical palliation [26]. In two other prospective trials it was found that EUS changed the treatment strategy in $75 \%$ of cases, with a tendency towards less costly, less risky and less invasive management $[27,28]$. The most important impact of EUS on the clinical management of patients with esophageal cancer is probably the decision making for a potential surgical curative resection. It has clearly been shown that T4 tumors are poor candidates for a surgical resection and should be offered palliative treatment [29]. Also patients with metastases at the celiac trunk have a poor prognosis and it is doubtful whether these patients are good candidates for a potential curative surgical resection [16]. EUS can also be used to make a choice in the optimal surgical strategy. At our center patients with a distal esophageal cancer preferably undergo a transhiatal esophagectomy, as this is associated with less morbidity [30]. However, when upper mediastinal lymph node metastases are detected by EUS-FNA, a transhiatal resection would not be appropriate, as it is not accompanied by an extended mediastinal lymph node dissection. In these patients a transthoracic resection with extended lymphadenectomy seems to be the treatment of choice. EUS-FNA is able to identify those patients preoperatively.

\section{Conclusions}

In the evaluation of patients with esophageal cancer, EUS will continue to play in important role. It is currently the only available modality that can image the esophageal wall layers with histological correlates. Additionally, it is the only modality, which enables to obtain tissue for confirmation of locoregional metastatic disease. A surgical esophagectomy is associated with a sig- nificant mortality and morbidity and therefore a cautious selection of patients who potentially benefit from a surgical procedure is of utmost importance. The introduction of new effective neoadjuvant modalities has further increased the challenge of staging and further management of patients with esophageal cancer.

\section{References}

${ }^{1}$ Murata Y, Napoleon B, Odegaard S. High-frequency endoscopic ultrasonography in the evaluation of superficial esophageal cancer. Endoscopy 2003; 35: 429-435

${ }^{2}$ Van Dam J, Rice TW, Catalano MF, Kirby T, Sivak MJr. High-grade malignant stricture is predictive of esophageal tumor stage. Risks of endosonographic evaluation. Cancer 1993; 71: 2910-2917

${ }^{3}$ Mallery S, Van Dam J. Increased rate of complete EUS staging of patients with esophageal cancer using the nonoptical, wire-guided echoendoscope. Gastrointest Endosc 1999; 50: 53-57

${ }^{4}$ Gines A, Wiersema MJ, Clain JE, Pochron NL, Rajan E, Levy MJ. Prospective study of a Trucut needle for performing EUS-guided biopsy with EUS-guided FNA rescue. Gastrointest Endosc 2005; 62: 597-601

${ }^{5}$ Enzinger PZ, Page DL, Fleming ID et al. AJCC Cancer Staging Manual (ed 6). New York: New York Springer: 200

${ }^{6}$ van Westreenen HL, Heeren PA, van Dullemen HM, van der Jagt EJ, Jager PL, Groen H, Plukker JT. Positron emission tomography with F-18fluorodeoxyglucose in a combined staging strategy of esophageal cancer prevents unnecessary surgical explorations. J Gastrointest Surg 2005; 9: 54-61

${ }^{7}$ Ide H, Nakamura T, Hayashi K, Endo T, Kobayashi A, Eguchi R, Hanyu F. Esophageal squamous cell carcinoma: pathology and prognosis. World J Surg 1994; 18: 321 - 330

${ }^{8}$ Rosch T. Endosonographic staging of esophageal cancer: a review of literature results. Gastrointest Endosc Clin N Am 1995; 5: 537-547

${ }^{9}$ Berger AC, Scott WJ. Noninvasive staging of esophageal carcinoma. J Surg Res 2004; 117: 127-133

${ }^{10}$ Pfau PR, Ginsberg GG, Lew RJ, Brensinger CM, Kochman ML. EUS predictors of long-term survival in esophageal carcinoma. Gastrointest Endosc 2001; 53: $463-469$

${ }^{11}$ Eloubeidi MA, Desmond R, Arguedas MR, Reed CE, Wilcox CM. Prognostic factors for the survival of patients with esophageal carcinoma in the U.S.: the importance of tumor length and lymph node status. Cancer 2002; 95: 1434-1443

12 Tio TL, Coene PP, Hartog Jager FC, Tytgat GN. Preoperative TNM classification of esophageal carcinoma by endosonography. Hepatogastroenterology 1990; 37: 376-381

${ }^{13}$ Kelly S, Harris KM, Berry E, Hutton J, Roderick P, Cullingworth J, Gathercole L, Smith MA. A systematic review of the staging performance of endoscopic ultrasound in gastro-oesophageal carcinoma. Gut 2001; 49: $534-539$

${ }^{14}$ Chen VK, Eloubeidi MA. Endoscopic ultrasound-guided fine needle aspiration is superior to lymph node echofeatures: a prospective evaluation of mediastinal and peri-intestinal lymphadenopathy. Am J Gastroenterol 2004; 99: 628-633

${ }^{15}$ Eloubeidi MA, Mason AC, Desmond RA, El Serag HB. Temporal trends $(1973-1997)$ in survival of patients with esophageal adenocarcinoma in the United States: a glimmer of hope? Am J Gastroenterol 2003; 98: $1627-1633$

${ }^{16}$ Marsman WA, van Wissen M, Bergman JJ, van Lanschot JJ, Obertop H, Tytgat GN, Fockens P. Outcome of patients with esophageal carcinoma and suspicious celiac lymph nodes as determined by endoscopic ultrasonography. Endoscopy 2004; 36: 961 - 965

${ }^{17}$ Eloubeidi MA, Wallace MB, Reed CE, Hadzijahic N, Lewin DN, Van Velse A, Leveen MB, Etemad B, Matsuda K, Patel RS, Hawes RH, Hoffman BJ. The utility of EUS and EUS-guided fine needle aspiration in detecting celiac lymph node metastasis in patients with esophageal cancer: a single-center experience. Gastrointest Endosc 2001; 54: 714 719

18 Vazquez-Sequeiros E, Wiersema MJ, Clain JE, Norton ID, Levy MJ, Romero Y, Salomao D, Dierkhising R, Zinsmeister AR. Impact of lymph node staging on therapy of esophageal carcinoma. Gastroenterology 2003; 125: 1626 - 1635 
${ }^{19}$ Prasad P, Schmulewitz N, Patel A, Varadarajulu S, Wildi SM, Roberts S, Tutuian R, King P, Hawes RH, Hoffman BJ, Wallace MB. Detection of occult liver metastases during EUS for staging of malignancies. Gastrointest Endosc 2004; 59: 49-53

${ }^{20}$ Flamen P, Lerut A, Van Cutsem E, Cambier JP, Maes A, De Wever W, Peeters M, De Leyn P, Van Raemdonck D, Mortelmans L. The utility of positron emission tomography for the diagnosis and staging of recurrent esophageal cancer. J Thorac Cardiovasc Surg 2000; 120: 10851092

${ }^{21}$ Isenberg G, Chak A, Canto MI, Levitan N, Clayman J, Pollack BJ, Sivak MJr. Endoscopic ultrasound in restaging of esophageal cancer after neoadjuvant chemoradiation. Gastrointest Endosc 1998; 48: 158 - 163

22 Kalha I, Kaw M, Fukami N, Patel M, Singh S, Gagneja H, Cohen D, Morris J. The accuracy of endoscopic ultrasound for restaging esophageal carcinoma after chemoradiation therapy. Cancer 2004; 101: 940-947

${ }^{23}$ Willis J, Cooper GS, Isenberg G, Sivak MJr, Levitan N, Clayman J, Chak A. Correlation of EUS measurement with pathologic assessment of neoadjuvant therapy response in esophageal carcinoma. Gastrointest Endosc 2002; 55: 655-661

24 Westerterp M, van Westreenen HL, Reitsma JB, Hoekstra OS, Stoker J, Fockens P, Jager PL, Eck-Smit BL, Plukker JT, van Lanschot JJ, Sloof GW. Esophageal cancer: CT, endoscopic US, and FDG PET for assessment of response to neoadjuvant therapy - systematic review. Radiology 2005; $236: 841-851$

${ }^{25}$ Harewood GC, Kumar KS. Assessment of clinical impact of endoscopic ultrasound on esophageal cancer. J Gastroenterol Hepatol 2004; 19: $433-439$

${ }^{26}$ Preston SR, Clark GW, Martin IG, Ling HM, Harris KM. Effect of endoscopic ultrasonography on the management of 100 consecutive patients with oesophageal and junctional carcinoma. Br J Surg 2003; 90: $1220-1224$

${ }^{27}$ Ainsworth AP, Mortensen MB, Durup J, Wamberg PA. Clinical impact of endoscopic ultrasonography at a county hospital. Endoscopy 2002; 34: $447-450$

${ }^{28}$ Nickl NJ, Bhutani MS, Catalano M, Hoffman B, Hawes R, Chak A, Roubein LD, Kimmey M, Johnson M, Affronti J, Canto M, Sivak M, Boyce HW, Lightdale CJ, Stevens P, Schmitt C. Clinical implications of endoscopic ultrasound: the American Endosonography Club Study. Gastrointest Endosc 1996; 44: $371-377$

${ }^{29}$ Fockens P, Kisman K, Merkus MP, van Lanschot JJ, Obertop H, Tytgat GN. The prognosis of esophageal carcinoma staged irresectable (T4) by endosonography. J Am Coll Surg 1998; 186: 17-23

${ }^{30}$ Hulscher JB, van Sandick JW, de Boer AG, Wijnhoven BP, Tijssen JG, Fockens P, Stalmeier PF, ten Kate FJ, van Dekken H, Obertop H, Tilanus HW, van Lanschot JJ. Extended transthoracic resection compared with limited transhiatal resection for adenocarcinoma of the esophagus. $\mathrm{N}$ Engl J Med 2002; 347: 1662 - 1669 